\title{
Respiratory Setback Associated with Extubation Failure in Extremely Preterm Infants
}

\author{
Dhruv Gupta $^{1}$, Rachel Greenberg ${ }^{2}$, Girija Natarajan ${ }^{3}$, Sanket Jani ${ }^{1}$, Amit Sharma ${ }^{1}$, \\ Michael Cotten ${ }^{2}$, Ronald Thomas ${ }^{1}$, and Sanjay Chawla ${ }^{3}$ \\ ${ }^{1}$ Children's Hospital of Michigan \\ ${ }^{2}$ Duke University \\ ${ }^{3}$ Wayne State University
}

November 17, 2020

\begin{abstract}
Background and Objectives: Extubation failure in preterm infants is associated with increased risk of mortality and morbidities. There is limited evidence to suggest if the increased morbidities are due to inherent differences among infants who fail or succeed; or whether these are due to a true respiratory setback among those who fail extubation. The aim of this study was to evaluate the respiratory status of infants who fail extubation and to assess the time taken for these infants to achieve pre-extubation respiratory status. Methods: This was a retrospective study of infants with birth weight [?]1,250 $\mathrm{g}$ who were born between January 2009 and December 2016. Infants were eligible if they failed first elective extubation. Extubation failure was defined as need for re-intubation within 5 days of extubation. Ventilator settings, blood gas parameters, respiratory severity score and ventilation index were used to assess respiratory status of infants. Results: Of 384 infants, $76 \%$ were successful and $24 \%$ failed extubation. Among those who failed extubation $91 \%, 77 \%$ and 56\% infants remained intubated at 24 hours, 72 hours and 7 days, respectively. Respiratory status was worse at 24 hours and 72 hours after re-intubation when compared to pre-extubation levels. The median times for respiratory severity score and ventilation index to reach pre-extubation levels were 4 days and 7 days respectively. Conclusion: Among preterm infants, failed elective extubation is associated with a significant setback in the respiratory status. Infants who fail an extubation attempt may not achieve pre-extubation respiratory status for many days after reintubation.
\end{abstract}

\section{Respiratory Setback Associated with Extubation Failure in Extremely Preterm Infants}

Dhruv Gupta, MD ${ }^{\mathrm{a}}$, Rachel G. Greenberg, MD, MB, MHS ${ }^{\mathrm{b}}$, Girija Natarajan, MD ${ }^{\mathrm{a}}$, Sanket Jani, MD ${ }^{\mathrm{a}}$, Amit Sharma, $\mathrm{MD}^{\mathrm{a}}$, Michael Cotten, MD, MHS ${ }^{\mathrm{b}}$, Ronald Thomas, $\mathrm{PhD}^{\mathrm{a}}$, Sanjay Chawla, MD ${ }^{\mathrm{a}}$

Affiliations : ${ }^{a}$ Department of Pediatrics, Wayne State University, Detroit, Michigan, USA; and ${ }^{\mathrm{b}}$ Department of Pediatrics, Duke University, Durham, North Carolina, USA

Address Correspondence to: Sanjay Chawla, Department of Pediatrics, 3901 Beaubien, Detroit, MI, USA, 48201. Email: schawla@dmc.org. Ph. 313745 1436, Fax: 3137455867

\section{Short title: Respiratory Setback with Extubation Failure}

Funding Source: The project was done with no specific funding support

Financial Disclosure: The authors have no financial relationships relevant to this article to disclose.

Conflict of Interest: The authors have no conflicts of interest relevant to this article to disclose

\section{Abbreviations :}


MV: Mechanical Ventilation

BPD: Bronchopulmonary Dysplasia

NICU: Neonatal Intensive Care Unit

NCPAP: Nasal Continuous Positive Airway Pressure

NIPPV: Nasal Intermittent Positive Pressure Ventilation

$\mathrm{PcO}_{2}$ : Partial pressure of carbon dioxide in arterial or capillary blood

RSS: Respiratory Severity Score

$\mathrm{FiO}_{2}$ : Fraction of Inspired Oxygen

ANS: Antenatal Steroids

GA: Gestational Age

PIH: Pregnancy-Induced Hypertension

MAP: Mean Airway Pressure

VI: Ventilation Index

CI: Confidence Interval

\section{ABSTRACT ( [?] 250 words)}

Background and Objectives: Extubation failure in preterm infants is associated with increased risk of mortality and morbidities. There is limited evidence to suggest if the increased morbidities are due to inherent differences among infants who fail or succeed; or whether these are due to a true respiratory setback among those who fail extubation. The aim of this study was to evaluate the respiratory status of infants who fail extubation and to assess the time taken for these infants to achieve pre-extubation respiratory status.

Methods: This was a retrospective study of infants with birth weight [?]1,250 $\mathrm{g}$ who were born between January 2009 and December 2016. Infants were eligible if they failed first elective extubation. Extubation failure was defined as need for re-intubation within 5 days of extubation. Ventilator settings, blood gas parameters, respiratory severity score and ventilation index were used to assess respiratory status of infants.

Results: Of 384 infants, $76 \%$ were successful and $24 \%$ failed extubation. Among those who failed extubation $91 \%, 77 \%$ and $56 \%$ infants remained intubated at 24 hours, 72 hours and 7 days, respectively. Respiratory status was worse at 24 hours and 72 hours after re-intubation when compared to pre-extubation levels. The median times for respiratory severity score and ventilation index to reach pre-extubation levels were 4 days and 7 days respectively.

\section{Conclusion:}

Among preterm infants, failed elective extubation is associated with a significant setback in the respiratory status. Infants who fail an extubation attempt may not achieve pre-extubation respiratory status for many days after reintubation.

\section{INTRODUCTION}

Approximately $80 \%$ of extremely preterm (gestational age $<28$ weeks) infants receive mechanical ventilation (MV) to maintain oxygenation and ventilation. ${ }^{1}$ A long cumulative duration of MV in preterm infants hospitalized in the Neonatal Intensive Care Unit (NICU) has been associated with higher rates of death and various neonatal morbidities, including bronchopulmonary dysplasia (BPD), upper airway injury, neurodevelopmental impairment, and nosocomial infections. ${ }^{1-5}$ An early extubation may reduce the risk of some of these complications. ${ }^{3,}{ }^{4,6}$ However, about $25 \%-40 \%$ of elective extubations in preterm infants are not successful. ${ }^{7-11}$ Unsuccessful extubations lead to a substantial proportion of infants receiving multiple courses 
of MV before first discharge from NICUs. ${ }^{12}$ Failed extubation has been independently associated with an increased risk of mortality, BPD, death or BPD, severe intracranial hemorrhage, longer hospitalization, and longer duration of supplemental oxygen and ventilator support. ${ }^{7,11,13-15}$ It is not known if the higher rate of morbidities noted among infants who fail extubation, compared to infants who are successfully extubated, are just associations due to inherent differences among infants who fail or succeed extubation and failure of extubation is just a marker of immaturity and sickness; or whether failed extubation is independently associated with a setback in the respiratory status of these infants. The aim of this study was to evaluate the pre-extubation and post reintubation respiratory status of infants who failed an extubation attempt and to assess the time taken for these infants to achieve the pre-extubation respiratory status after reintubation.

\section{METHODS}

\section{Study Design}

This was a retrospective cohort study that included preterm infants born at Hutzel Women's Hospital, Detroit, MI, from January 2009 to December 2016. The study was approved by the Institutional Review Board at Wayne State University, Detroit.

\section{Study Population}

All preterm infants with birth weights less than 1,250 g who were admitted to the NICU at Hutzel Women's Hospital were screened. Infants were eligible for the study if they received MV via an endotracheal tube and had an elective extubation. Infants who were never intubated, died before an extubation attempt was made or had an unplanned extubation prior to an elective extubation attempt were excluded from the analysis. Data were collected for only the first elective extubation attempt. Twelve patients were excluded from the analysis as they were part of another study on extubation readiness - Automated Prediction of Extubation Readiness (clinicaltrials.gov NCT01909947). The decisions for initial endotracheal intubation, timing of extubation, post-extubation support, and need for reintubation were at the discretion of the primary clinical team.

\section{Definitions}

Extubation failure was defined as need for reintubation within 5 days of the first elective extubation..$^{7,8}$ Respiratory status was assessed using ventilator set rate, fraction of inspired oxygen $\left(\mathrm{FiO}_{2}\right)$ received, mean airway pressure and peak inspiratory pressure given by the ventilator along with the respiratory severity score (RSS: product of mean airway pressure and $\mathrm{FiO}_{2}$ ) and ventilation index (VI: product of the set rate, partial pressure of carbon dioxide in arterial or capillary blood $\left(\mathrm{Pco}_{2}\right)$, and the difference between peak inspiratory and positive end-expiratory pressure divided by 1,000 ). Ventilation index was used as an objective measure of adequacy of ventilation in response to the respiratory support provided, ${ }^{16}$ and respiratory severity score (RSS) was used as an objective marker of oxygenation in relation to mean airway pressure received by the patient. ${ }^{17}$ We also analyzed blood gas parameters that included arterial or capillary blood gas $\mathrm{pH}$ and $\mathrm{PCO}_{2}$, and compared pre-extubation levels with levels 24 hours and 72 hours post reintubation.

Among those infants who failed extubation, time to reach pre-extubation respiratory status (such as RSS and VI) was defined as time to reach same level of these respiratory parameters or extubation to non-invasive ventilation, whichever occurred first.

Gestational age was estimated based on best obstetric approximation using early ultrasonography findings, date of last menstrual period, or modified Ballard score in that order. ${ }^{18}$ Small for gestational age (SGA) was defined as per the Olsen definition. ${ }^{19}$ The usual practice at our center through the study period was to use noninvasive ventilation whenever possible (NCPAP: nasal continuous positive airway pressure or NIPPV: nasal intermittent positive pressure ventilation), and to limit endotracheal intubation and MV to infants who were persistently apneic ([?]3 episodes in a 24-hour period) and/or failed attempted noninvasive ventilation. Extubation was usually attempted at ventilator set rates of 16 to 20 breaths per minute, mean airway pressure of less than $8 \mathrm{~cm} \mathrm{H}_{2} \mathrm{O}$, and $\mathrm{FiO}_{2}$ below 0.4, with blood gas $\mathrm{pH}$ greater than 7.25 and $\mathrm{Pco}_{2}$ less than $60 \mathrm{~mm} \mathrm{Hg}$. 


\section{Statistical Analysis}

Pre-extubation RSS, VI, ventilator set rate, mean airway pressure (MAP), peak inspiratory pressure (PIP), $\mathrm{FiO}_{2}$ being provided through the ventilator, blood gas $\mathrm{PcO}_{2}$, and blood gas $\mathrm{pH}$ were compared with these parameters at 24 hours and 72 hours after reintubation. The comparisons were performed using the Wilcoxon signed rank test. A $P$ value of $<.05$ was considered statistically significant. Statistical analysis was conducted using Stata version 16.1 (College Station, TX).

\section{RESULTS}

During the study period, a total of 384 infants met the inclusion criteria. Of these 384 infants, 290 (76\%) succeeded and 94 (24\%) failed extubation.

\section{Perinatal and Peri-Extubation Characteristics}

The 94 infants that failed extubation had a median gestational age (GA) of 25.5 (IQR 24-27) weeks, median birth weight of 780 (680-914) grams, $14 \%$ infants were SGA, $52 \%$ were male, $51 \%$ had an APGAR score of [?] 6 at 5 minutes of age, median age at first extubation attempt was 4 (2-12) days, median post menstrual age at extubation was 27 (26-28) weeks.

\section{Time to reach pre-extubation support}

Among those who failed elective extubation, median time to reach pre-extubation RSS level was 4 days (IQR 2-7) and pre-extubation VI level was 7 days (IQR 3-14).

Among infants who failed extubation, 86 (91\%), $72(77 \%)$ and $53(56 \%)$ infants remained intubated 24 hours, 72 hours and 7 days after re-intubation, respectively.

\section{Comparison of respiratory and blood gas parameters}

Respiratory parameters including RSS, VI, ventilator set rate, MAP, PIP and FiO2 at 24 hours and 72 hours were compared to the pre-extubation levels. All respiratory parameters were noted to be significantly worse at 24 hours and 72 hours post reintubation, when compared to pre-extubation levels. The pre-extubation blood gas $\mathrm{pH}$ and pre-extubation $\mathrm{PCO}_{2}$ were compared to post-reintubation blood gas $\mathrm{pH}$ and $\mathrm{PCO}_{2}$ at 24 hours, and 48 hours. Blood gas parameters measured at 24 hours and 72 hours post re-intubation were noted to be significantly worse when compared to pre-extubation levels (Table 1; Figure 1-3).

\section{DISCUSSION}

The current study noted that $24 \%$ of the extreme preterm infants failed their first elective extubation. These results are comparable to previous studies of extremely preterm infants, which have demonstrated extubation failure of approximately 23 to $40 \%$. ${ }^{7-11}$. The time taken to achieve comparable pre-extubation respiratory support (RSS: 4 days with IQR of 2-7 days; VI: 7 days with IQR of 3-14 days) is concerning and provides an estimate of the significant respiratory setback among infants who fail extubation. All respiratory and blood gas parameters were significantly worse at both 24 and 72 hours post re-intubation when compared with pre-extubation levels.

There could be multiple potential reasons for respiratory setback among these infants after failed extubation. It is possible that some infants develop atelectasis and loss of functional residual capacity due to lack of adequate respiratory support post extubation or during the intubation attempt. ${ }^{20}$ Extubation failure requiring reintubation is not a benign process and may be associated with multiple complications. Endotracheal intubation is associated with discomfort to the patient, and wrong position of endotracheal tube can cause airway trauma along with hemodynamic instability. ${ }^{21-24}$ There is also a risk of introduction of infectious micro-organisms every time a new endotracheal tube is inserted. ${ }^{25}$ Reported rates of successful intubations for preterm neonates are between $50 \%$ and $73 \%$ with a long time (51 \pm 28 seconds) needed for intubation. ${ }^{26,27}$ Endotracheal intubations have also been associated with alterations in brain function as monitored by electroencephalography. ${ }^{28}$ The current study provides more insight into the pathophysiology of failed extubation and outcomes of preterm infants related to respiratory setback. 
This study has some limitations. Endotracheal intubation, extubation, and reintubation were at the discretion of the clinical team. We did not have data on occurrence of other complications during peri-extubation period such as sepsis, and NEC. We did not explore the reasons for extubation failure in this study. Also, there was no sub-group

analysis done based on the timing of reintubation, other than the predefined criteria of 5 days. All infants were born in a single center, which reduces generalizability of the study. Strengths of the study were inclusion of all eligible infants using pre-defined criteria with no selection bias, and use of objective criteria to compare the respiratory status of these infants in relation to extubation failure.

\section{CONCLUSION}

Preterm infants who failed their first extubation attempt had significant respiratory setback. Most infants had worse respiratory status post reintubation for multiple days.

Table 1. Comparison of respiratory and blood gas parameters

\begin{tabular}{lllll}
\hline & $\begin{array}{l}\text { Pre-extubation } \\
(\mathrm{n}=94)\end{array}$ & $\begin{array}{l}24 \text { hrs. post } \\
\text { re-intubation } \\
(\mathrm{n}=86)\end{array}$ & $\begin{array}{l}72 \text { hrs. post } \\
\text { re-intubation } \\
(\mathrm{n}=72)\end{array}$ & P Value \\
Variable $^{\mathrm{a}}$ & $5.60(4.43-8.14)$ & $13.10(9.36-19.20)$ & $11.43(7.82-16.40)$ & $<.001^{\mathrm{b}}<.001^{\mathrm{c}}$ \\
$\mathrm{VI}$ & $1.64(1.40-1.90)$ & $2.24(1.60-3.08)$ & $1.79(1.48-2.62)$ & $<.001^{\mathrm{b}}<.001^{\mathrm{c}}$ \\
$\mathrm{RSS}$ & $14(14-16)$ & $16(14-17)$ & $16(14-16)$ & $<.001^{\mathrm{b}}<.001^{\mathrm{c}}$ \\
$\mathrm{PIP}\left(\mathrm{cm} \mathrm{H}_{2} \mathrm{O}\right)$ & $26(22-35)$ & $22(18-31)$ & $<.001^{\mathrm{b}}<.001^{\mathrm{c}}$ \\
Ventilator rate $($ per & $15(14-18)$ & $7.1(6.2-7.9)$ & $6.8(6.0-7.7)$ & $<.001^{\mathrm{b}}<.001^{\mathrm{c}}$ \\
minute) & & $30(25-38)$ & $28(23-35)$ & $<.001^{\mathrm{b}} .04^{\mathrm{c}}$ \\
$\mathrm{MAP}\left(\mathrm{cm} \mathrm{H} \mathrm{H}_{2} \mathrm{O}\right)$ & $6.2(5.6-6.9)$ & $7.32(7.26-7.37)$ & $7.30(7.25-7.35)$ & $.04^{\mathrm{b}} .007^{\mathrm{c}}$ \\
$\mathrm{Fio}_{2}(\%)$ & $25(21-30)$ & $45(38-52)$ & $46(42-51)$ & $<.001^{\mathrm{b}}<.001^{\mathrm{c}}$ \\
$\mathrm{pH}^{\mathrm{Pco}}(\mathrm{mmHg})$ & $7.34(7.29-7.37)$ & & & \\
\hline
\end{tabular}

a Data are given as Median (Interquartile range)

b Comparison between variables, pre-extubation vs $24 \mathrm{hrs}$. post re-intubation

${ }^{c}$ Comparison between variables, pre-extubation vs $72 \mathrm{hrs}$. post re-intubation

Abbreviations: RSS, respiratory severity score; $\mathrm{Fio}_{2}$, fraction of inspired oxygen; MAP, mean airway pressure; PIP, peak inspiratory pressure; VI, ventilation index; $\mathrm{Pco}_{2}$, Partial pressure of carbon dioxide in arterial or capillary blood; $\mathrm{pH}$, Arterial or capillary blood gas $\mathrm{pH}$

Figure 1: Changes in RSS Changes in VI 


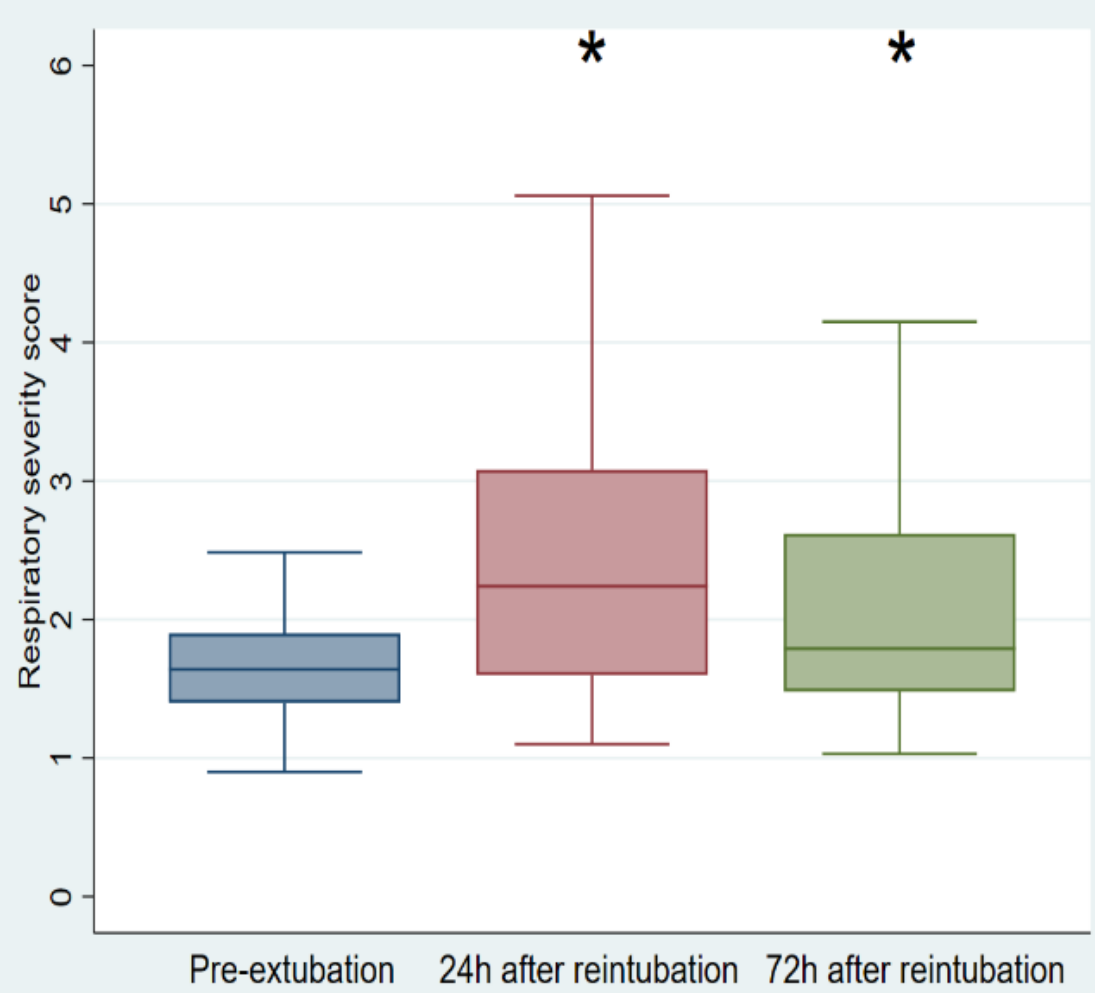




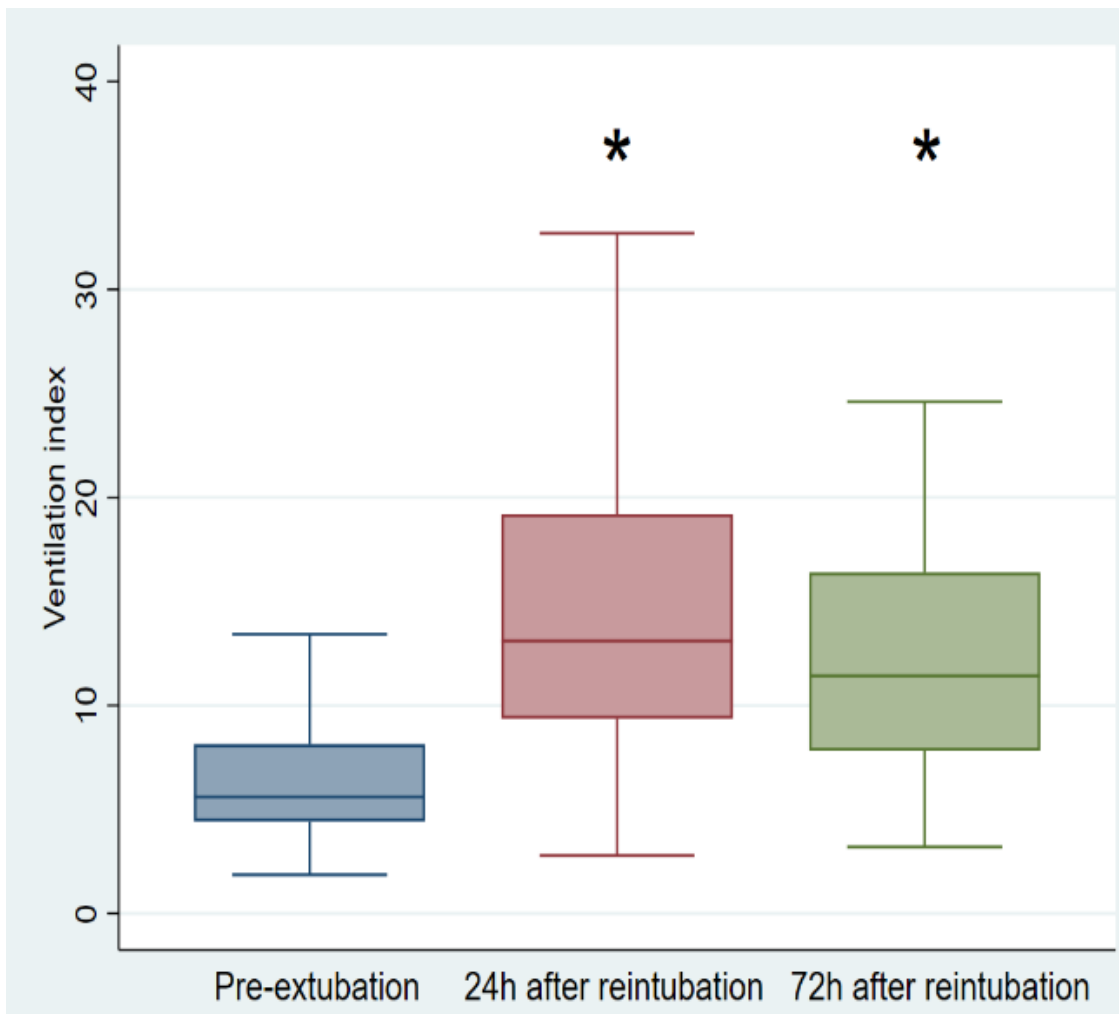

Data are given as Median with Interquartile range

Abbreviations: RSS, respiratory severity score; VI, ventilation index; ${ }^{*}, P$ value $<.05$

Figure 2: Changes blood gas $\mathrm{pH}$

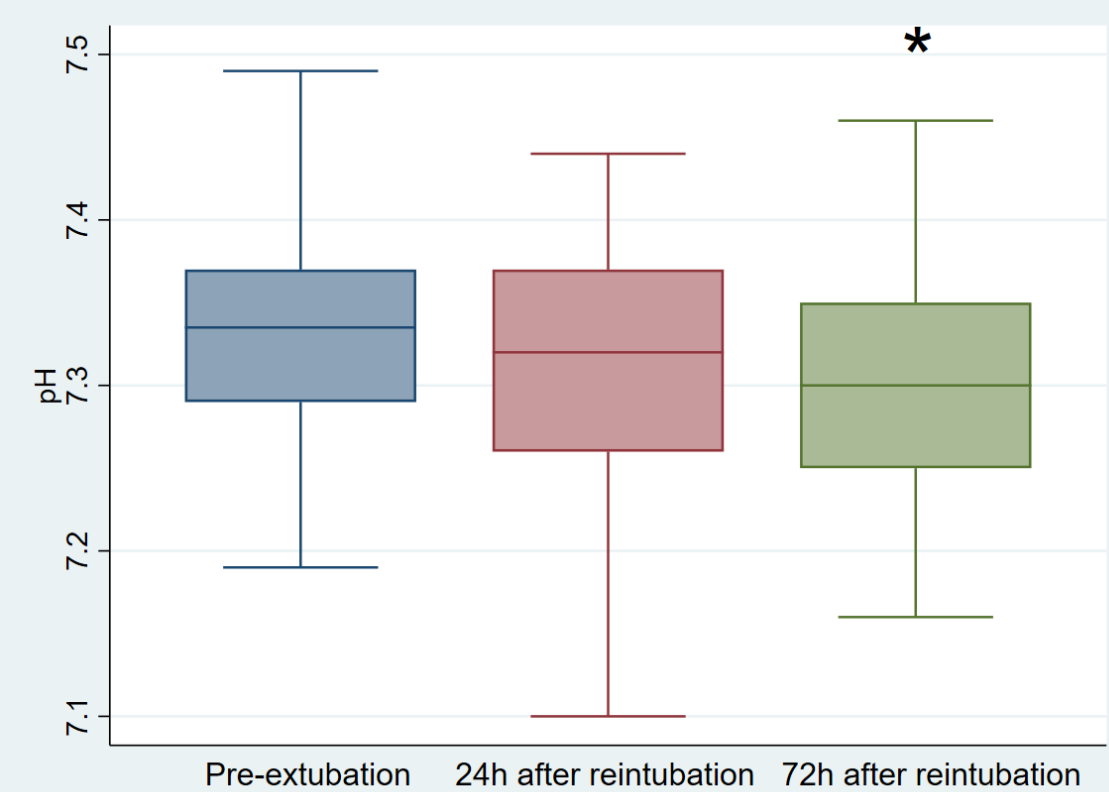


Data are given as Median with Interquartile range $(\mathrm{mmHg})$

Abbreviations: $\mathrm{pH}$, Arterial or capillary blood gas $\mathrm{pH} ;{ }^{*}, P$ value $<.05$

Figure 3: Changes blood gas $\mathrm{PcO}_{2}$

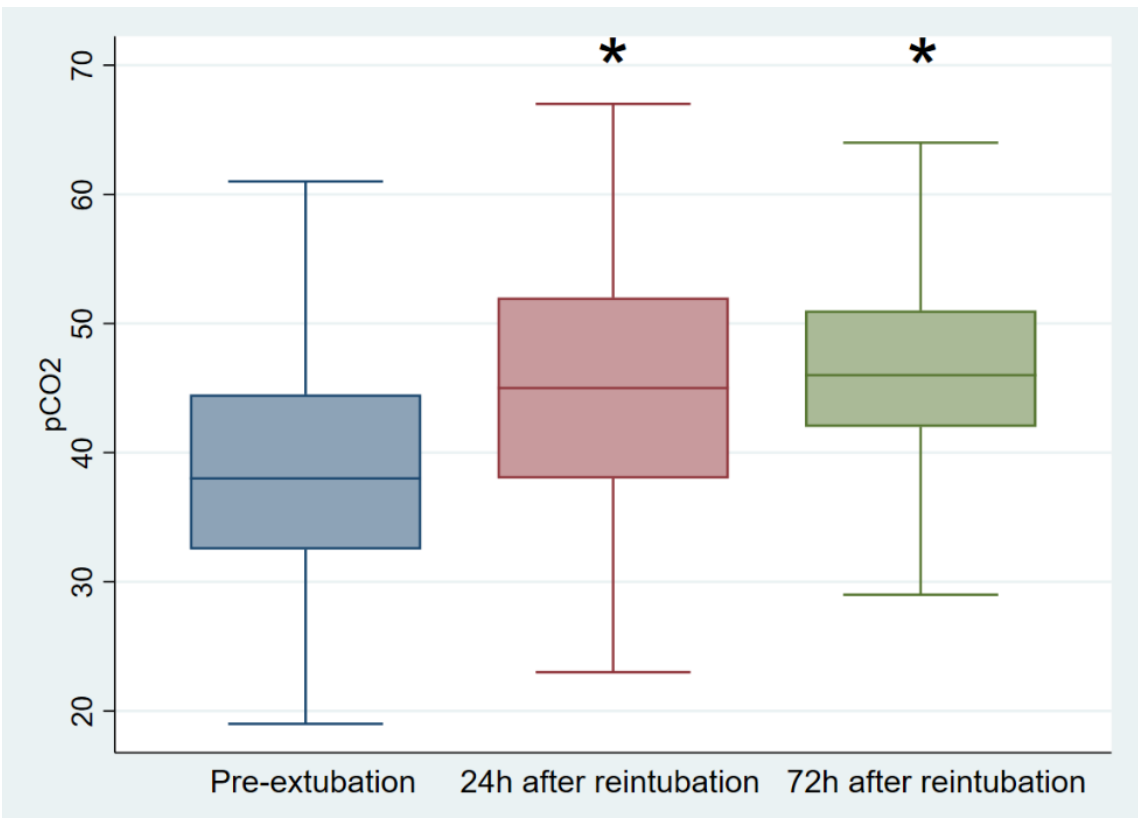

Data are given as Median with Interquartile range $(\mathrm{mmHg})$

Abbreviations: $\mathrm{PcO}_{2}$, Partial pressure of carbon dioxide in arterial or capillary blood; ${ }^{*}, P$ value $<.05$

\section{References}

[1] Stoll BJ, Hansen NI, Bell EF, Walsh MC, Carlo WA, Shankaran S, et al. Trends in Care Practices, Morbidity, and Mortality of Extremely Preterm Neonates, 1993-2012. JAMA. 2015;314:1039-51.

[2] Walsh MC, Morris BH, Wrage LA, Vohr BR, Poole WK, Tyson JE, et al. Extremely low birthweight neonates with protracted ventilation: mortality and 18-month neurodevelopmental outcomes. J Pediatr. 2005;146:798-804.

[3] Sant'Anna GM, Keszler M. Weaning infants from mechanical ventilation. Clin Perinatol. 2012;39:543-62.

[4] Miller JD, Carlo WA. Pulmonary complications of mechanical ventilation in neonates. Clin Perinatol. 2008;35:273-81, x-xi.

[5] Jensen EA, DeMauro SB, Kornhauser M, Aghai ZH, Greenspan JS, Dysart KC. Effects of Multiple Ventilation Courses and Duration of Mechanical Ventilation on Respiratory Outcomes in Extremely LowBirth-Weight Infants. JAMA Pediatr. 2015;169:1011-7.

[6] Berger J, Mehta P, Bucholz E, Dziura J, Bhandari V. Impact of early extubation and reintubation on the incidence of bronchopulmonary dysplasia in neonates. Am J Perinatol. 2014;31:1063-72.

[7] Chawla S, Natarajan G, Shankaran S, Carper B, Brion LP, Keszler M, et al. Markers of Successful Extubation in Extremely Preterm Infants, and Morbidity After Failed Extubation. J Pediatr. 2017;189:1139 e2. 
[8] Gupta D, Greenberg RG, Sharma A, Natarajan G, Cotton M, Thomas R, Chawla S. A predictive model for extubation readiness in extremely preterm infants. J Perinatol. 2019 Dec;39(12):1663-1669. doi: 10.1038/s41372-019-0475-x. Epub 2019 Aug 27

[9] Giaccone A, Jensen E, Davis P, Schmidt B. Definitions of extubation success in very premature infants: a systematic review. Arch Dis Child Fetal Neonatal Ed. 2014;99:F124-7.

[10] Hermeto F, Martins BM, Ramos JR, Bhering CA, Sant'Anna GM. Incidence and main risk factors associated with extubation failure in newborns with birth weight < 1,250 grams. J Pediatr (Rio J). 2009;85:397-402.

[11] Manley BJ, Doyle LW, Owen LS, Davis PG. Extubating Extremely Preterm Infants: Predictors of Success and Outcomes following Failure. J Pediatr. 2016;173:45-9.

[12] Kirpalani H, Millar D, Lemyre B, Yoder BA, Chiu A, Roberts RS, et al. A trial comparing noninvasive ventilation strategies in preterm infants. N Engl J Med. 2013;369:611-20.

[13] Epstein SK, Ciubotaru RL, Wong JB. Effect of failed extubation on the outcome of mechanical ventilation. Chest. 1997;112:186-92.

[14] Baisch SD, Wheeler WB, Kurachek SC, Cornfield DN. Extubation failure in pediatric intensive care incidence and outcomes. Pediatr Crit Care Med. 2005;6:312-8.

[15] Thille AW, Harrois A, Schortgen F, Brun-Buisson C, Brochard L. Outcomes of extubation failure in medical intensive care unit patients. Crit Care Med. 2011;39:2612-8.

[16] Bohn DJ, James I, Filler RM, Ein SH, Wesson DE, Shandling B, et al. The relationship between $\mathrm{PaCO} 2$ and ventilation parameters in predicting survival in congenital diaphragmatic hernia. J Pediatr Surg. 1984;19:666-71.

[17] Ballard RA, Truog WE, Cnaan A, Martin RJ, Ballard PL, Merrill JD, et al. Inhaled nitric oxide in preterm infants undergoing mechanical ventilation. N Engl J Med. 2006;355:343-53.

[18] Ballard JL, Khoury JC, Wedig K, Wang L, Eilers-Walsman BL, Lipp R. New Ballard Score, expanded to include extremely premature infants. J Pediatr. 1991;119:417-23.

[19] Olsen IE, Groveman SA, Lawson ML, Clark RH, Zemel BS. New intrauterine growth curves based on United States data. Pediatrics. 2010;125(2):e214-24. Epub 2010/01/27. doi: 10.1542/peds.2009-0913. PubMed PMID: 20100760).

[20] Odita JC, Kayyali M, Ammari A. Post-extubation atelectasis in ventilated newborn infants. Pediatr Radiol. 1993;23(3):183-185. doi:10.1007/BF02013827

[21] Walner DL, Loewen MS, Kimura RE. Neonatal subglottic stenosis-incidence and trends. Laryngoscope. 2001;111:48-51.

[22] Venkatesh V, Ponnusamy V, Anandaraj J, Chaudhary R, Malviya M, Clarke P, et al. Endotracheal intubation in a neonatal population remains associated with a high risk of adverse events. Eur J Pediatr. 2011;170:223-7.

[23] Schuman TA, Jacobs B, Walsh W, Goudy SL. Iatrogenic perinatal pharyngoesophageal injury: a disease of prematurity. Int J Pediatr Otorhinolaryngol. 2010;74:393-7.

[24] Schedlbauer EM, Todt I, Ernst A, Seidl RO. Iatrogenic tracheal rupture in children: A retrospective study. Laryngoscope. 2009;119:571-5.

[25] Levine SA, Niederman MS. The impact of tracheal intubation on host defenses and risks for nosocomial pneumonia. Clin Chest Med. 1991 Sep;12(3):523-43.

[26] Kamlin CO, O'Connell LA, Morley CJ, Dawson JA, Donath SM, O'Donnell CP, et al. A randomized trial of stylets for intubating newborn infants. Pediatrics. 2013;131:e198-205. 
[27] Bismilla Z, Finan E, McNamara PJ, LeBlanc V, Jefferies A, Whyte H. Failure of pediatric and neonatal trainees to meet Canadian Neonatal Resuscitation Program standards for neonatal intubation. J Perinatol. 2010;30:182-7.

[28] Shangle CE, Haas RH, Vaida F, Rich WD, Finer NN. Effects of endotracheal intubation and surfactant on a 3-channel neonatal electroencephalogram. J Pediatr. 2012;161:252-7. 